\title{
Expressão facial de emoções de crianças com deficiência visual e videntes: diferentes procedimentos de evocação, registro e avaliação obtidos em uma intervenção
}

\section{Facial emotions expression in visual impairment and seers children: differents evocation, registration and evaluation procedures obtained in an intervention}

La expresión facial de las emociones de los niños con discapacidad visual y videntes: diferentes procedimientos de evocación, registro y evaluación obtenidos en una intervención

\author{
Bárbara Carvalho Ferreira* \\ Universidade Federal dos Vales do Jequitinhonha e Mucuri - UFVJM, Diamantina, \\ Minas Gerais, Brasil
}

\section{Zilda Aparecida Pereira Del Prette**}

Universidade Federal de São Carlos - UFSCar, São Carlos, São Paulo, Brasil

\section{Almir Del Prette***}

Universidade Federal de São Carlos - UFSCar, São Carlos, São Paulo, Brasil

\begin{abstract}
RESUMO
Considerando os procedimentos para evocação, registro e julgamento das expressões faciais de emoções, bem como a carência de pesquisas que avaliem essas diferentes metodologias, o presente estudo teve como objetivo analisar a sensibilidade diferencial dos procedimentos de evocação e registro das expressões faciais de emoções (EFE) de crianças com deficiência visual e videntes obtidas antes, durante e após um programa de intervenção que visou ensinar e aperfeiçoar o repertório de EFE na interface com as habilidades sociais. Participaram da pesquisa, que adotou um delineamento pré e pós-teste com sujeito único, com múltiplas sondagens e replicações intra e entre sujeitos, e intervenção com 21 sessões, três crianças cegas, três com baixa visão e três videntes, assim como os pais, professores e um juiz, que avaliaram as expressões faciais de emoções das crianças em diferentes momentos, evocadas e avaliadas de formas diversas, além de serem registradas por fotografias e filmagens. Os resultados mostraram que na sondagem que ocorreu após a intervenção a porcentagem de acertos das expressões faciais de emoções de todas as crianças foi maior, seja no registro por fotografia ou por filmagem. Além disso, o repertório de expressão facial de emoções de todos os participantes, avaliado pelos pais, professoras e juiz, foi aprimorado e mantido após o programa de
\end{abstract}


intervenção, assim como a qualidade da expressividade de emoções pela face.

Palavras-chave: expressão facial de emoções, avaliação, intervenção, deficiência visual.

\begin{abstract}
Considering the evocation, registration and judgment procedures of facial emotions expressions, and the lack of researches to evaluate these different methodologies, this study aimed to analyze the differential sensitivity of the evocation and registration procedures of facial emotions expressions (FEE) of visual impairment and seers children obtained before, during and after an intervention program that aimed to teaching and improving the repertoire of FEE at interface with social skills. Participated in the research, which adopted a pre-and post-test design with single subject, with multiple polls and replications within and between subjects, and intervention with 21 sessions, three visually impaired children, three with low vision and three seers, as parents, teachers and a judge, which evaluated the facial emotions expressions of children at different moments, evoked and evaluated various ways, besides being recorded by photographs and footages. The results indicated in the poll that after intervention the percentage of corrects about the all children facial emotions expressions was higher. In addition, the facial emotions repertoire of all participants, evaluated by parents, teachers and judge, was improved and maintained after the intervention program, as well as the face emotions expressiveness quality.
\end{abstract}

Keywords: facial expression of emotions, evaluation, intervention, visual impairment.

\title{
RESUMEN
}

Considerándose los procedimientos de evocación, registro y juzgamiento de las expresiones faciales de las emociones, así como la falta de investigación que evalúen estas diferentes metodologías, el presente estudio tuvo como objetivo analizar la sensibilidad diferencial de los procedimientos de evocación y registro de las expresiones faciales de las emociones (EFE) de los niños con discapacidad visual y videntes antes, durante y después de un programa de intervención que propuso enseñar y perfeccionar el repertorio de EFE en interfaz con las habilidades sociales. Participaron de la investigación, que utilizó un diseño pre y post test con único sujeto, con múltiples sondeos y replicaciones intra- y entre los sujetos, e intervención con 21 sesiones, tres niños ciegos, tres con baja visión y tres videntes, así como los padres, los maestros y un juez, que evaluaron las expresiones faciales de las emociones de los niños en diferentes momentos, evocados y evaluados de diversas maneras, además de haber sido registradas por medio de fotografías y filmación. Los resultados mostraron que en el sondeo, que se llevó a cabo después de la intervención, el porcentaje de aciertos de las expresiones faciales de las emociones de todos los niños fue superior, tanto en el registro en la fotografía como en la filmación. Además, el repertorio de la expresión facial de las emociones de todos los participantes, evaluados por los padres, maestros y juez, fue perfeccionado y mantenido después del programa de intervención, así como la calidad de la expresividad de las emociones por la cara.

Palabras clave. expresión facial de emociones, evaluación, intervención, discapacidad visual. 
A expressão de emoções ocorre principalmente pela face, mas não apenas, nem, tampouco, isoladamente. Estudos sobre as expressões faciais de emoções, mais especificamente, alegria, tristeza, medo, raiva, nojo e surpresa, apontam que estas seis emoções apresentam um caráter universal, no sentido de que são identificadas pelos membros da cultura (Ekman, 2004). Os estudos de Ekman, Sorenson e Friesen (1969), Ekman \& Friesen (1971), Ekman (2004) e Plutchik (2002) apoiam a hipótese de que as expressões faciais das seis emoções básicas são inatas e universais, ou seja, a expressão de emoções básicas costuma ser idêntica em todos os povos. Porém, segundo revisão de literatura realizada por Miguel (2015), "o contexto cultural e a história individual demonstram exercer influência predominante sobre a avaliação de quais estímulos provocam emoções e em quais momentos pode-se ou deve-se expressar quais emoções" (p. 159).

Ainda sobre os estudos que investigaram a universalidade da expressão das emoções básicas, Eibl-Eibesfeldt (1975) identificou a expressividade facial das seis emoções em crianças com cegueira e surdez congênita. No caso das crianças com deficiência visual, algumas pesquisas indicam que o repertório de expressividade facial de emoções destas pessoas é preservado e semelhante ao das pessoas sem essa limitação e com acesso a aprendizagem visual, e, portanto, aos modelos e feedbacks gestuais (Castanho, 1996; Matsumoto \& Willingham, 2009; Tinti, 2003). Entretanto, outras pesquisas indicam que crianças com deficiência visual apresentam alguns comprometimentos na expressão facial de emoções, tanto em termos de repertório menos expressivo como menos regulado e controlado pelas variáveis contextuais, culturais e pessoais (Costa, Del Prette, Cia \& Del Prette, 2005; Tröster \& Brambring, 1992). Diante disso, é consenso em grande parte dos estudos sobre essa temática (Anzano \& Rubio, 1995; Castanho, 1996; Castanho, Moifrel, Severiano \& Ribeiro, 2003; Costa, 2005; Ferreira, 2008; Godoy, 2007; Otta, 1994; Tinti, 2003) a importância e necessidade de se programar intervenções nesta área, associados ou não ao treinamento de habilidades sociais, isso porque a capacidade de expressar emoções pela face, além de ser considerada um dos componentes indispensáveis de algumas classes de habilidades sociais imprescindíveis na infância, como empatia, autocontrole, é também uma das principais subclasses da habilidade de expressividade emocional (Del Prette \& Del Prette, 2005).

Um exemplo deste tipo de programa de intervenção foi desenvolvido por Ferreira e Del Prette (2013). Nesse estudo foi apresentado e avaliado um programa de intervenção visando à promoção da expressividade facial de emoções (EFE), enquanto componente indispensável no desempenho de habilidades sociais (HS). A intervenção incluiu um conjunto de procedimentos aplicado, 
individualmente a três crianças cegas, três com baixa visão e três videntes, sob um delineamento de múltiplas sondagens e replicações intra e entre sujeitos, ao longo de 21 sessões. Os dados, obtidos por meio de escala de habilidades sociais (SSRS-BR) e de fichas e protocolos de avaliação de fotografias e filmagens. Os resultados mostraram mudanças relevantes em termos de melhoria da EFE bem como seu impacto sobre as classes de habilidades sociais. No entanto, algumas questões ainda permaneceram e não puderam ser incluídas no escopo daquele estudo. Uma delas, foco do presente estudo, refere-se à descrição mais detalhada e avaliação da sensibilidade diferencial dos procedimentos empregados na evocação, registro e julgamento da EFE dessas crianças.

Nos estudos dessa área, têm sido utilizados procedimentos diversificados de evocação, registro e julgamento da expressão facial de emoções (Silva, 1986). Esses três aspectos envolvem decisões metodológicas que devem equilibrar parcimônia e qualidade dos dados.

A primeira das decisões a ser tomada é quanto à forma de evocação da expressão de emoções pela face, que pode ocorrer em resposta a: (a) estímulos, naturais ou disparadores (que presumivelmente evocariam emoções pré-determinadas), como ocorreu no estudo de Tinti (2003); (b) instruções para que o sujeito se imagine na presença de determinados estímulos e mostre as expressões que apresentaria nestas situações evocadoras de emoção; (c) instruções para que o sujeito mostre a expressão que faria se estivesse sentindo determinada emoção (Grosselin, Kirouac \& Doré, 1997; Silva, 1986). As demandas evocadoras das expressões faciais de emoções devem se aproximar ao máximo da situação natural, pois quanto mais similaridade maior a confiabilidade dos dados (Silva, 1986).

Uma segunda decisão do pesquisador refere-se à forma de registro da expressividade não verbal. Segundo Silva (1986), a forma de registro mais comumente utilizada em pesquisas sobre expressões faciais de emoções é a fotografia, dado seu baixo custo e facilidade de uso. No entanto, esse autor reconhece que a maior objeção ao uso de fotografias é a perda de informações sobre as modulações temporais e mutacionais da expressão facial. A alternativa para garantir um registro contínuo da expressão facial de uma determinada emoção, em termos de início, meio e fim, é a filmagem. Além dessas informações temporais, a filmagem possibilita o registro da duração do evento e de outros componentes não verbais que acompanham e complementam a expressão facial de emoção (Ekman \& Friesen, 1975, 1971).

Uma terceira decisão metodológica, discutida na área, é a escolha das técnicas de julgamento das expressões faciais de emoções. De acordo com Silva (1986), alguns dos principais procedimentos de julgamento das expressões faciais de emoções são: (1) escolha do 
nome da emoção, a partir de uma lista dada pelo pesquisador (técnica mais utilizada); (2) nomeação livre, sem auxílio da referida lista, o que exige prévia determinação de sinônimos para cada emoção; (3) escolha, entre várias fotografias, da que melhor representa a emoção do personagem na história narrada pelo pesquisador. O julgamento pode ocorrer, também, por meio de uma técnica de comparação entre as mudanças apresentadas facialmente e os sinais característicos de cada emoção (Silva, 1986), a partir da descrição detalhada dos músculos faciais envolvidos na expressividade de cada emoção, realizada por Ekman e Friesen (1975). Essa avaliação pode variar desde expressividade facial mínima até a expressão completa de emoção (Silva, 1986), dependendo de quantos sinais faciais característicos de cada emoção são identificados. Em alguns estudos, por exemplo, o de Costa et al. (2005) foram utilizados três diferentes procedimentos de julgamento. Os diferentes procedimentos de evocação, registro e julgamento das expressões faciais constituem um desafio ao pesquisador, que precisa equilibrar a parcimônia de sua pesquisa com a evidente complementaridade dessas diferentes alternativas em cada uma dessas etapas. O uso isolado de cada uma dessas alternativas tem gerado pesquisas pouco comparáveis entre si e com resultados discordantes, dependendo do método empregado. Além disso, quando se trata de avaliar intervenções voltadas para a promoção de expressões faciais de emoções, pode-se questionar qual ou quais desses métodos seriam mais sensíveis ao impacto de tais programas ou procedimentos empregados (Ferreira, 2012).

Dadas as considerações anteriores, o presente estudo teve como objetivo analisar a sensibilidade diferencial dos procedimentos de evocação e registro das expressões faciais de emoções (EFE) de crianças com deficiência visual e videntes obtidas antes, durante e após um programa de intervenção que visou ensinar e aperfeiçoar o repertório de EFE na interface com as habilidades sociais.

\section{Método}

\section{Participantes}

De uma amostra de 29 crianças com e sem deficiência visual, nove foram selecionadas para participação na pesquisa. Elas tinham idade entre sete e 10 anos e estavam matriculadas entre $01^{\circ}$ e $5^{\circ}$ ano do Ensino Fundamental de escolas comuns, sendo três com cegueira congênita (duas do gênero masculino e uma do gênero feminino), três com baixa visão (duas do gênero feminino e um do gênero masculino) e três videntes (duas do gênero masculino e uma do gênero feminino). Participaram, ainda, como avaliadores, oito mães, 
um pai e as professoras das nove crianças com deficiência visual e videntes, além de um juiz, estudante de Graduação em Psicologia, do gênero feminino.

\section{Materiais e Instrumentos}

Materiais para evocação das expressões faciais de emoções - Nas avaliações antes e após o programa de intervenção foram utilizados os seguintes materiais: histórias gravadas em áudio, com sons possíveis de serem associados a determinadas emoções, e trechos de filmes ou desenhos com personagens expressando emoção ou contexto levando à associação com um sentimento. Já para evocação das emoções antes e após cada módulo (avaliação contínua), foram utilizados estímulos naturais e disparadores com diversos objetos que permitiam às crianças explorar os sentidos do olfato, tato e audição (Laplane \& Batista, 2008), tais como: alegria, presentes/brindes para a criança; tristeza, áudios com pessoas relatando histórias tristes que Ihes aconteceram; medo, leitura da história "A caixa perdida" com pedido à criança para retirar, de uma caixa, objetos associados a este sentimento; nojo, apresentação dos objetos com diferentes texturas e odores acondicionados de modo a não serem percebidos (tato, visão, olfato) antes do momento apropriado; raiva, reapresentação oral de situações em que a criança teria sentido raiva, conforme informação coletada junto aos pais e professoras e confirmados pela criança, com solicitação para que esta falasse sobre o ocorrido e expressasse sua reação; surpresa, apresentações de objetos que se modificavam, por exemplo, um sapo de plástico de aproximadamente cinco centímetros que, quando colocado em um recipiente com água, aumentava de tamanho, ficando com 60 centímetros, além de outros materiais (ver Ferreira, 2012). Para evocação das expressões faciais de emoções no pré-teste e no pós-teste foram utilizados materiais diferentes. Todos estes materiais foram avaliados em estudo piloto, quanto à sua aplicabilidade, por uma professora cega, uma criança cega e outra vidente.

Materiais utilizados para registro - Para registro das expressões faciais de emoções foi utilizado máquina fotográfica e filmadora.

Ficha de Avaliação das Expressões Faciais de Emoções Evocadas por meio de Instruções: Versão juiz - Utilizada pelo juiz para avaliar as expressões faciais de emoções das crianças, obtidas por meio de fotografias e filmagens antes e após o programa de intervenção. Esta ficha continha o código da fotografia ou da filmagem referente à expressão facial de cada emoção por uma criança, e a seguinte instrução: "Olhando para a fotografia/filmagem do rosto dessa criança, o que você acha que ele(a) está sentindo?".

Ficha de Avaliação das Expressões Faciais de Emoções Evocadas por meio de Instruções: Versão pais e professores - A ficha era dividida 
em duas seções. Na primeira (Escolha por resposta livre), continha as instruções: "Olhando para esta fotografia do rosto do(a) seu/sua filho/aluno(a), o que você acha que ele (a) está sentindo?". A segunda parte (Escolha entre opções de resposta) continha fotografias e cartões, cada um deles com o nome de uma emoção, com a instrução: "Olhando para esta fotografia do rosto do(a) seu/sua filho/aluno(a), qual a alternativa destes cartões mais corresponde ao que ele(a) está sentindo?".

Ficha de Avaliação das Expressões Faciais de Emoções e Demais Componentes Não Verbais Evocados por meio de Estímulos Naturais e/ou Disparadores (filmagens): Versão Juiz - Ficha com as instruções: (1) "Olhando para a filmagem do rosto dessa criança, o que você acha que ele(a) está sentindo?". (2) "Olhando para a filmagem dessa criança, além da expressão facial, ela apresenta outros componentes não verbais (gestos, mudanças de postura, contato visual, movimentos com a cabeça) coerentes com a expressividade dessa emoção?". A ficha, utilizada para avaliação ao longo da intervenção (avaliação contínua - antes e após cada módulo do programa), continha uma opção de resposta fechada (sim ou não), seguida por uma opção de detalhamento, em caso de resposta afirmativa; (3) "Como você reconheceu o que a criança estava sentindo"?, com três opções de resposta, (a) pelo rosto/face; (b) pelos gestos e/ou mudanças de postura; (c) pelo rosto e gestos.

Ficha de Avaliação da Qualidade das Expressões Faciais de Emoções obtidas por meio de Fotografias: Versão Juiz - Ficha contendo uma escala, com alternativas de respostas para cada emoção, que permite avaliar a qualidade da EFE em termos da ausência ou presença de sinais faciais clássicos, característicos de cada emoção (conforme Ekman \& Friesen, 1975; Ekman, 2004): 0 = Repertório ruim (não apresenta nenhuma característica clássica na expressão facial de uma determinada emoção); 1 = Repertório razoável (apresenta uma característica clássica na expressão facial de uma determinada emoção); 2 = Repertório bom (apresenta duas características clássicas na expressão facial de uma determinada emoção); $3=$ Repertório muito bom (apresenta três características clássicas na expressão facial de uma determinada emoção).

Procedimentos de intervenção, coleta e análise dos dados

Programa de intervenção - O programa de intervenção, conduzido pela primeira autora, teve como objetivos ensinar as crianças a: discriminar e expressar os sinais característicos de cada emoção na sua própria face; discriminar as condições do ambiente relacionadas com a expressão de cada emoção; estabelecer relação entre a expressão de sentimento pela face e pelos demais componentes não verbais, com as classes de habilidades sociais importantes nas 
relações interpessoais. O programa foi conduzido individualmente, com 21 sessões de aproximadamente 60 minutos cada, de três a cinco vezes por semana, organizados em oito módulos, uma para cada emoção básica, além de um inicial e final. As sessões apresentavam uma estrutura semelhante, mas com flexibilidade para alterações de procedimentos e materiais adaptados às características, recursos e especificidades do grau de comprometimento visual. Para a avaliação do programa, foi adotado um delineamento de sujeito único, com múltiplas sondagens e replicações intra e entre sujeitos com diferentes graus de comprometimento visual.

Cuidados éticos - O projeto de pesquisa foi aprovado pelo Comitê de Ética da Universidade Federal de São Carlos (CEP/UFSCar, Processo $352 / 2007)$. Ao longo de todas as etapas de avaliação e do programa de intervenção, cuidados especiais foram tomados em relação às emoções negativas, no sentido de se garantir que não produziriam desconforto além daquele do momento de exposição. Pais e professores foram informados sobre os procedimentos, solicitando-se que, caso observassem qualquer desconforto da criança, entrassem em contato com a pesquisadora. Além disso, durante as atividades, a pesquisadora sondava se a criança estava gostando, oferecendo opções de continuar ou interromper a atividade ou mudar para outra. Segundo alguns pais, seus filhos relataram expectativa e curiosidade sobre a atividade evocadora de medo ("A Caixa Perdida"). Na última sessão, a pesquisadora solicitou que relatassem as atividades preferidas e esta foi a mais frequentemente referida.

A coleta de dados ocorreu antes, durante e depois da intervenção com cada criança individualmente. Segue-se a descrição dos procedimentos adotados para evocação, registro e avaliação da expressão facial das crianças em cada um desses momentos.

Evocação das expressões faciais de emoções por meio de estímulos naturais e disparadores, registrado por filmagem - Antes e após cada módulo do programa de intervenção relacionado a uma determinada emoção, na evocação das expressões faciais de emoções, a pesquisadora apresentava à criança os materiais referentes a cada emoção, permitindo que tocassem, sentissem o cheiro, explorando com os sentidos, por exemplo, para a tentativa de evocação de surpresa, as crianças, tanto as videntes como as com deficiência visual, eram incentivadas tocarem o material antes de ser inserido na água e ao final. Todas as atividades foram registradas por filmagem.

Evocação das expressões faciais de emoções por meio de instruções, registradas por fotografias e filmagem - Para evocação das expressões faciais de emoções por meio de instruções, antes e após o programa de intervenção, foram adotados os seguintes procedimentos com cada criança: (a) apresentação de histórias gravadas em áudio e trechos de filmes ou desenhos com personagens expressando emoção ou contexto levando à associação com um 
sentimento; (b) conversa com a criança a respeito da emoção do personagem da história ou das emoções possíveis de serem associadas a determinados sons; (c) conversa com a criança sobre situações associadas ao sentimento evocado no momento, por exemplo, "Alegria", quando o time ganha no futebol ou quando se ganha um presente ou "Medo" de algum animal, de escuro, de ladrão, de ficar sozinho; (d) instruções verbais para a criança apresentar a expressão facial referida pela pesquisadora (por exemplo, "A gente mostra no rosto quando estamos alegres. Faça uma cara alegre para eu ver").

A expressão facial fotografada e filmada era aquela apresentada pela criança quando a pesquisadora pedia que ela a mostrasse no rosto. A sequência das instruções para fotografar e filmar cada expressão facial de emoção (primeiro alegria, depois tristeza, raiva, nojo e, por fim, surpresa) foi escolhida a partir dos dados obtidos nos estudos piloto (ver Ferreira, 2012). Todos os procedimentos de evocação e registro foram aperfeiçoados e testados em estudo piloto.

Sensibilidade diferencial de procedimentos e informantes na avaliação da expressividade emocional - As expressões faciais de emoções foram julgadas por diferentes avaliadores (pais, professoras e juiz) e com diversos procedimentos (escolha livre, escolha com opções, avaliação molecular). Com os pais e professoras, a avaliação das fotografias foi realizada com dois procedimentos: no primeiro, a pesquisadora informava que Ihes mostraria as fotos da criança e que eles deveriam responder perguntas como, "Olhando para a fotografia do rosto de seu/sua filho(a)/aluno(a), o que você acha que ele(a) está sentindo?". Foram aceitos sinônimos, tais como: Alegria (feliz, contente); Raiva (bravo); Surpresa (susto); Nojo (asco). No segundo procedimento, a pesquisadora pedia que escolhessem um dos cartões apresentados, em resposta à pergunta: "Olhando para a fotografia do rosto do(a) seu/sua filho/aluno(a), qual a alternativa destes cartões mais se aproxima do que ele(a) pode estar sentindo?".

Com o juiz, houve cinco procedimentos. O primeiro procedimento foi de escolha livre; o segundo, após treino para julgamento de expressões faciais de emoções, o juiz recebeu um arquivo digital com todas as fotografias das expressões faciais de emoções das crianças, dispostas aleatoriamente e lhe era pedido que respondesse na Ficha de Avaliação das Expressões Faciais de Emoções por Fotografias Versão juiz. No terceiro, a pesquisadora entregou outro arquivo digital, agora com as filmagens das expressões faciais (obtidas concomitantemente às fotos) com a Ficha de Avaliação das Expressões Faciais de Emoções por Filmagem a ser preenchida para cada criança. No quarto, o juiz era solicitado a avaliar a qualidade da expressividade emocional da criança pela face nas fotos recebidas em um arquivo digital, com as fotografias das expressões faciais de emoções e preenchendo a Ficha de Avaliação da Qualidade das 
Expressões Faciais de Emoções Obtidas por meio de Fotografias. E no último, avaliava as expressões faciais de emoções evocadas por estímulos naturais e disparadores, a partir de trechos gravados em DVD e organizados em sequência aleatória para cada criança, juntamente com a Ficha de Avaliação das Expressões Faciais de Emoções e dos Demais Componentes Não Verbais Evocados por meio de Estímulos Naturais e/ou Disparadores (filmagens).

Todas as pontuações obtidas foram organizadas em planilhas do Excel. Essas pontuações foram tabuladas e analisadas por meio de estatística descritiva, gráficos e figuras ilustrativas.

\section{Resultados}

Na Tabela 1, apresenta-se o conjunto de dados da avaliação do juiz a respeito das expressões faciais de emoções evocadas por instruções e das registradas por fotografia e filmagem.

Tabela 1

Avaliações Corretas do Juiz Sobre as Fotografias e Filmagens das Expressões Faciais de Emoções Evocadas por Instruções

\begin{tabular}{|c|c|c|c|c|c|c|c|c|c|c|c|c|}
\hline \multirow{2}{*}{ Participante } & \multicolumn{2}{|c|}{ Alegria } & \multicolumn{2}{|c|}{ Tristeza } & \multicolumn{2}{|c|}{ Medo } & \multicolumn{2}{|c|}{ Raiva } & \multicolumn{2}{|c|}{ Nojo } & \multicolumn{2}{|c|}{ Surpresa } \\
\hline & Pré & $\mathrm{Pos}_{\mathrm{s}}$ & $\mathrm{Br}_{\mathrm{e}}$ & $\mathrm{P}_{63}$ & $\mathrm{P}_{\mathrm{x} i}$ & $\mathrm{P}_{03}$ & Pré & $\mathrm{Pobs}_{0}$ & Pré & $P_{0 s}$ & $\mathrm{Pr} i$ & $\mathrm{Pos}_{0}$ \\
\hline Pl (Cego- A) & I & 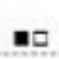 & 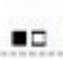 & ש & & 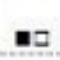 & & 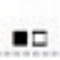 & & 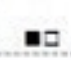 & & - \\
\hline$P_{2}\left(C_{050}-\xi\right)$ & $=$ & $=$ & E & $=$ & & $=$ & & 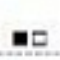 & $=$ & 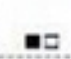 & & $=$ \\
\hline P3 (Cego - - ) & ב & 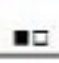 & ם & $m$ & & ם & & 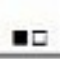 & & 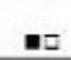 & & ם \\
\hline $\mathrm{P} 4(\mathrm{BV} \cdot \vec{A})$ & $=$ & $=$ & & 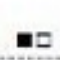 & & $=$ & $=$ & $=c$ & $=$ & 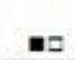 & & 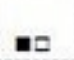 \\
\hline P5 (BV - 9) & ש & $=$ & 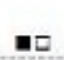 & 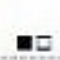 & & 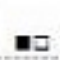 & & . & ש & $\mathbb{E}$ & & שם \\
\hline P6 (BV - - ) & 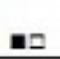 & 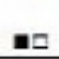 & & $\underline{m}$ & & I & & 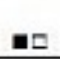 & II & 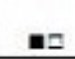 & & 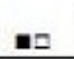 \\
\hline P7 (Vidente - E) & 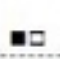 & 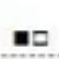 & & בת & & בת & בת & 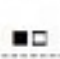 & I & 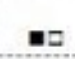 & $\square$ & 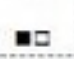 \\
\hline PS (Vidente - İ) & $=$ & a & 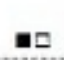 & 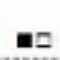 & & 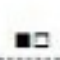 & 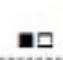 & $=c$ & a & 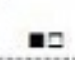 & & 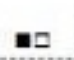 \\
\hline P7 (Vidente - P) & $=$ & 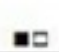 & & 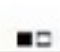 & & 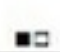 & & 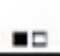 & I & 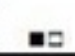 & & 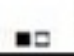 \\
\hline
\end{tabular}

Nota BV = Baixa visão; $\stackrel{\rho}{=}$ Sexo feminino; $\hat{\delta}=$ Sexo masculino;

Avaliação juiz fotografia $=\mathbf{m} ;$ Avaliação juiz filmagem $=$ 口.

Observa-se que a porcentagem de julgamentos corretos na avaliação das expressões faciais no pré-teste foi de $46,2 \%$, sendo que destes, $88 \%$ foram identificados por meio de fotografias e filmagens, e 0 restante, $12 \%$, apenas por filmagem. No pós-teste, todas as emoções foram corretamente identificadas, a maioria delas $(94,4 \%)$ nas duas 
formas de registro. Dentre as que foram identificadas somente em uma forma de registro, pode-se destacar a expressão de medo de P3 e P4 apenas por filmagem $(3,7 \%)$ e raiva de P5 por fotografia $(1,6 \%)$.

Com base nos acertos, os dados mostram as emoções que o juiz identificou com maior facilidade: (a) alegria, (100\% nas duas formas de registro, no pré e no pós-teste); (b) nojo, com 100\% de acertos no pós-teste por ambas as formas de registro, e $77,7 \%$ no pré-teste, sendo que em seis das sete vezes que foi identificada ocorreu o julgamento correto por fotografia e filmagem, e uma única vez apenas por filmagem; (c) tristeza, com $100 \%$ de acertos no pós-teste por ambas as formas de registro, e $55,5 \%$ de julgamentos corretos no pré-teste, sendo que em $44,4 \%$ a identificação desta emoção ocorreu por fotografias e filmagem, e uma única vez apenas por filmagem.

As emoções menos identificadas pelos juízes foram medo e surpresa. No pré-teste, medo não foi identificado na face de nenhuma criança e a surpresa apenas na face de P7, quando o registro foi por filmagem. No pós-teste, ambas as emoções foram identificadas na face de todas as crianças ( $100 \%$ para fotografias e filmagens de surpresa e $77,7 \%$ $\%$ de medo; $22,2 \%$ apenas por filmagem de medo). Foi constatada, também, pouca diferença entre os acertos do juiz nos registros de expressão facial das crianças com deficiência visual e videntes. As diferenças observadas indicam que mais emoções foram identificadas na face das crianças videntes, seguida pelas com baixa visão, e por fim pelas cegas, principalmente, nos dados de pré-teste.

A Tabela 2 apresenta os resultados do julgamento de pais e professores sobre as expressões faciais de emoções evocadas por instruções e registradas por fotografias, nas duas etapas de avaliação, com o procedimento de resposta livre e de escolha entre opções. 
Tabela 2

Avaliações Corretas de Pais e Professoras Sobre o Registro Fotográfico das

Expressões Faciais de Emoções com Resposta Livre e com Escolha entre Opções

\begin{tabular}{|c|c|c|c|c|c|c|c|c|c|c|c|c|}
\hline \multirow{2}{*}{ Participante } & \multicolumn{2}{|c|}{ Alegria } & \multicolumn{2}{|c|}{ Tristeza } & \multicolumn{2}{|c|}{ Medo } & \multicolumn{2}{|c|}{ Raiva } & \multicolumn{2}{|c|}{ Nojo } & \multicolumn{2}{|c|}{ Surpresa } \\
\hline & Res & Pós & Pré & Pós & Psi & Pós & Roke & Pós & Rsi & Pós & Pris & Pós \\
\hline P1 Cego ô & $\Delta=0$ & $\Delta=\bullet$ & $\Delta$ & $\Delta=\bullet$ & & $\Delta$ & & $\Delta$ & & $\Delta$ & & $\Delta=0$ \\
\hline P2 Cego $\widehat{\delta}$ & & $\Delta \| \subset \bullet$ & $\Delta \square$ & $\Delta=0$ & & $\Delta=c$ & & $\Delta \|$ & & $\Delta \boldsymbol{M}$ & & $\Delta=$ \\
\hline P3 Cego $?$ & $\Delta=0$ & $\Delta=\bullet$ & - & $\Delta=\bullet$ & - & $\Delta=\bullet$ & & $\Delta \mathbf{A r}$ & & $\Delta=\bullet$ & & $\Delta=0$ \\
\hline P4 BV o & $\Delta=0$ & $\Delta=c$ & & $\Delta \boldsymbol{\Delta} \cdot \bullet$ & & $\Delta=$ & $\Delta$ & $\Delta \boldsymbol{\Delta}=\boldsymbol{\bullet}$ & $\Delta=\bullet$ & $\Delta=\bullet$ & & $\Delta=\bullet$ \\
\hline P5 BV 9 & $\Delta=$ & $\Delta=$ & & $\Delta=$ & & & & $\Delta \square$ & $\Delta=$ & $\Delta \square$ & & $\Delta$ \\
\hline P6 BV $ㅇ$ & $\Delta=\bullet$ & $\Delta=\bullet$ & & $\Delta=\bullet$ & & $\Delta \cdot$ & & $\Delta \mathbf{n}=\bullet$ & $\Delta=\cdot$ & $\Delta \mathbf{A n}$ & & $\Delta=\bullet$ \\
\hline P7 Vidente 8 & $\Delta=0$ & $\Delta=\bullet$ & $\Delta=$ & $\Delta-\bullet$ & & $\Delta=\bullet$ & $\Delta$ & $\Delta=\bullet$ & $\Delta=\bullet$ & $\Delta=0$ & & $\Delta=0$ \\
\hline P8 Vidente $\delta$ & $\Delta=\bullet$ & $\Delta=\bullet$ & - & $\Delta=\bullet$ & & $\Delta=\bullet$ & $\Delta$ & $\Delta \mathbf{A n}$ & $\Delta$ & $\Delta=\bullet$ & & $\Delta=\bullet$ \\
\hline P7 Vidente 9 & $\Delta=\bullet$ & 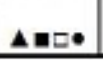 & & $\Delta$. & & $\Delta$ & & $\Delta \| \cdot$ & $\Delta$ & $\Delta=\bullet$ & & $\Delta$ \\
\hline
\end{tabular}

Nota. BV $=$ Baixa visão; $\stackrel{\varphi}{=}=$ Sexo feminino; $\hat{\delta}=$ Sexo masculino; Avaliação

professora com escolha entre opções $=\boldsymbol{\Lambda} ;$ Avaliação professora por resposta livre $=\square$;

Avaliação pais com escolha entre opções $=\mathbf{m} ;$ Avaliação pais por resposta livre $=\bullet$.

Das 108 expressões faciais avaliadas, 76 (70,3\%) delas foram julgadas corretamente pelos pais, professoras ou ambos, sendo que $63(82,8 \%)$ dos julgamentos ocorreram quando os avaliadores tinham acesso aos cartões com os nomes das emoções e $45(59,2 \%)$ quando julgaram as emoções por resposta livre. Os dados indicam que as professoras conseguiram identificar mais emoções que os pais, tanto na etapa de escolha entre opções como na de resposta livre, e que ambos os avaliadores tiveram mais dificuldades de julgar as emoções quando não tinham acesso aos cartões com os nomes das emoções, principalmente, os pais.

Assim como na avaliação do juiz por fotografias, os pais e as professoras identificaram mais emoções no pós-teste do que no pré. Além disso, os dados indicam poucas diferenças entre os julgamentos dos três avaliadores, principalmente entre juiz e professoras (quando estas tinham acesso aos cartões para escolha). No caso dos pais, na etapa de escolha entre opções, a diferença entre suas avaliações e as do juiz e das professoras foi de oito e sete emoções, respectivamente. Quanto às emoções mais e menos identificadas, os dados dos familiares são semelhantes aos do juiz, ou seja, alegria, nojo e tristeza, nesta ordem, foram as emoções mais identificadas, enquanto surpresa e medo foram as menos identificadas. 
As expressões faciais de emoções das crianças também foram evocadas por meio de estímulos naturais e disparadores. Os dados que se seguem referem-se às avaliações que foram realizadas antes e após cada módulo de ensino do programa de intervenção (avaliação contínua). As avaliações do juiz são apresentadas na Tabela 3.

Tabela 3

Avaliações Corretas do Juiz sobre as Filmagens (Avaliação Contínua) das Expressões

Faciais de Emoções, nas Sondagens de Pré-teste e Pós-teste.

\begin{tabular}{|c|c|c|c|c|c|c|c|c|c|c|c|c|}
\hline \multirow{3}{*}{ Participante } & \multicolumn{12}{|c|}{ Emoções } \\
\hline & \multicolumn{2}{|c|}{ Alegria } & \multicolumn{2}{|c|}{ Tristeza } & \multicolumn{2}{|c|}{ Medo } & \multicolumn{2}{|c|}{ Raiva } & \multicolumn{2}{|c|}{ Nojo } & \multicolumn{2}{|c|}{ Surpresa } \\
\hline & Pré. & Pós & Pré & Pós & Pré & Pós & Pré & Pós & Pré & Pós & Pré & Pós \\
\hline P1 Cego ó & - & - & - & $\Delta$ & & - & & - & & - & & - \\
\hline P2 Cego 8 & - & - & & $\Delta$ & & - & - & - & - & - & & - \\
\hline P3 Cego $q$ & - & - & & $\Delta$ & - & - & & - & & $\Delta$ & - & $\Delta$ \\
\hline P4 BV 8 & - & - & - & $\Delta$ & & - & & - & - & - & & $\Delta$ \\
\hline P5 BV? & - & - & - & $\boldsymbol{\Lambda}$ & & $\boldsymbol{\Delta}$ & & - & $\Delta$ & - & & - \\
\hline P6 BV 9 & . & - & & $\Delta$ & & - & & - & - & - & & $\Delta$ \\
\hline P7 Vidente 6 & & - & & $\Delta$ & & $\Delta$ & - & - & - & - & - & $\Delta$ \\
\hline P\& Vidente $\hat{6}$ & - & - & $\bullet$ & $\boldsymbol{\Lambda}$ & - & - & & - & - & \pm & & - \\
\hline P7 Vidente 9 & - & - & & $\boldsymbol{\Delta}$ & & $\boldsymbol{\Delta}$ & a & - & & - & & - \\
\hline
\end{tabular}

Identificação pelo rosto e gestos/postura $=\mathbf{A}$

Comparando-se os dados da Tabela 3 com os da Tabela 1, constatase que mais emoções foram identificadas quando a evocação ocorreu por instrução ( 78 de 108 , ou $72,22 \%$ ) do que por meio de demandas naturais ( 70 de 108 , ou $64,81 \%$ ). Nas duas etapas de evocação, mais emoções foram identificadas no pós do que no pré-teste e as emoções mais identificadas foram alegria e nojo. Quanto às menos identificadas, a única diferença foi para tristeza que, junto com surpresa e medo, foram as menos identificadas quando a evocação ocorreu por demandas naturais.

No que se refere aos demais componentes não verbais, destacam-se nos dados de pós-teste a expressividade de tristeza que, além de ser apresentada por todas as crianças, ocorreu por meio da face, dos gestos e da postura (ombros caídos, olhar para baixo e movimento de "cabisbaixo"). Outros gestos e mudanças na postura também foram frequentes, como o de repulsa com mãos (esticando-as para frente), o de voltar o corpo para trás com contração rápida dos ombros na expressão de nojo; o curvar do corpo para trás e prender a respiração na expressividade de medo; erguer os ombros e a cabeça 
em sobressalto na expressão de surpresa. Além disso, algumas crianças cegas (P1 e P2) apresentavam alguns movimentos estereotipados, como o corpo para frente e para trás ou de um lado para outro, mas que diminuíram nas filmagens após a intervenção.

Além da análise molar, ou seja, das expressões faciais de emoções (evocadas por meio de instruções) como um todo, estas também foram julgadas pela ausência e presença dos sinais faciais característicos de cada emoção na face, cuja escala variava de 0 (ruim) a 3 (muito bom), conforme avaliado pela Ficha de Avaliação da Qualidade das Expressões Faciais de Emoções obtidas por meio de Fotografias: Versão Juiz. Para apresentação destes dados, segue a Figura 1.

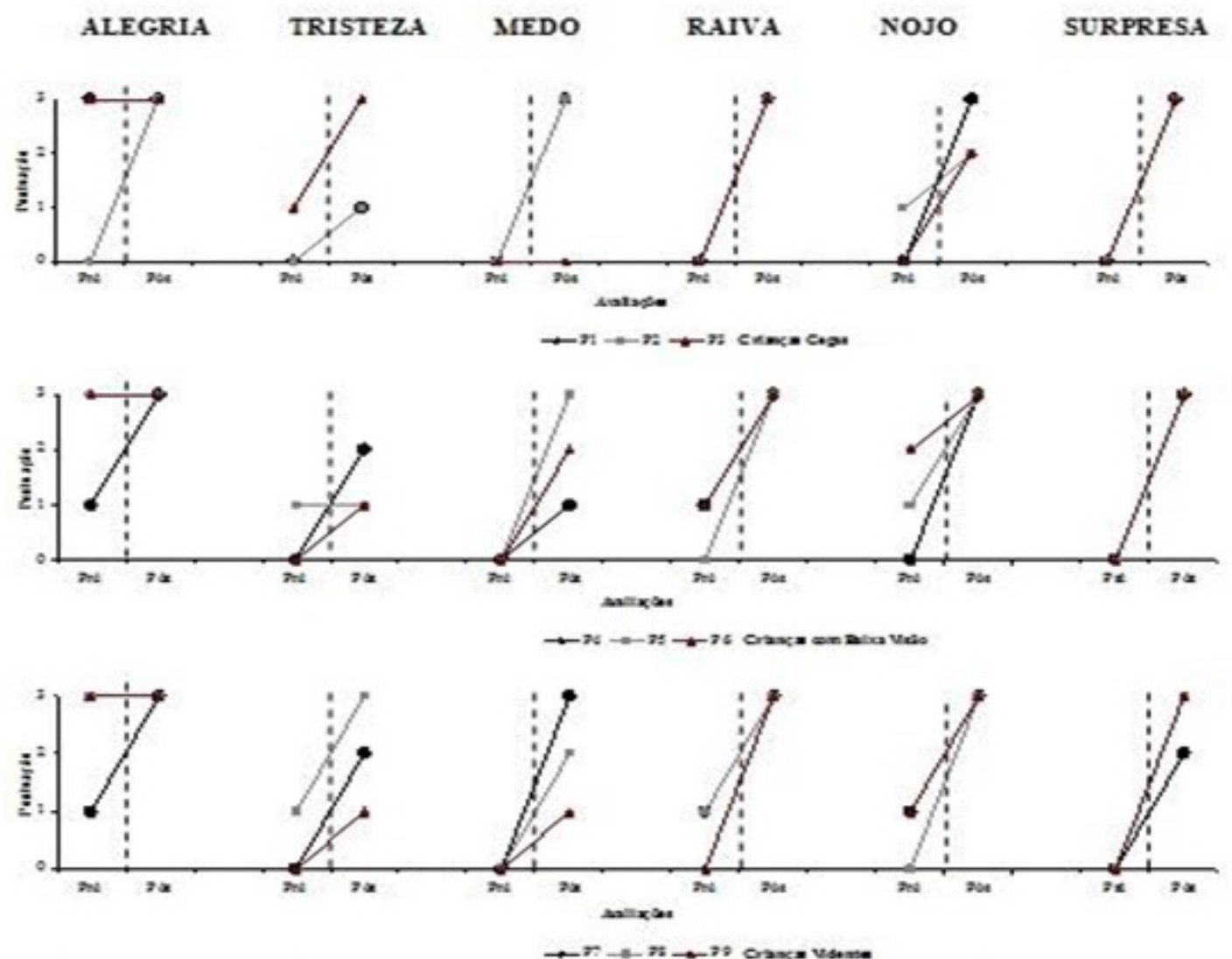

Figura 1. Qualidade das expressōes faciais de emoçōes dos nove participantes, conforme avaliação por juiz com base em fotografias.

De modo geral, observa-se uma melhora na qualidade da expressão facial de emoção após a intervenção, em todos os subgrupos de crianças e para todas as emoções avaliadas. Os ganhos mais significativos, em termos da presença de sinais característicos de cada emoção na face, foram para: (a) surpresa, em que a expressividade facial dos nove participantes foi avaliada inicialmente como ruim (ausência de todos os sinais faciais característicos desta emoção) sendo que, no pós-teste, oito passaram para uma 
expressividade muito boa e um (P7, vidente) para boa; (b) raiva, em que todos participantes apresentavam inicialmente expressão facial ruim ou apenas razoável, mas melhoraram após a intervenção, para a expressividade muito boa; (c) medo, em que os nove participantes apresentavam inicialmente expressão facial ruim e melhoraram após a intervenção. Ganhos também ocorreram para as outras emoções, mas aquela que as crianças apresentaram mais dificuldade de expressividade foi tristeza. Mesmo tendo melhora no pós-teste, cinco crianças ainda apresentaram repertório apenas razoável na expressividade desta emoção.

\section{Discussão}

O presente estudo avaliou a sensibilidade diferencial de formas diversas de evocação, registro e julgamento das expressões faciais de emoções comparando dados obtidos antes e depois de um programa de intervenção. Os resultados sugerem uma coerência entre a identificação das emoções pelo juiz e o julgamento de boa qualidade de expressividade, em termos da presença de sinais faciais característicos de cada emoção. Como a avaliação da qualidade das expressões faciais de emoções envolvia a análise de cada músculo facial, pode-se inferir que, quanto melhor a qualidade da expressão, mais prontamente ela é identificada (e vice-versa).

Considerando os dados obtidos a partir da evocação por meio de instruções, constatou-se que a emoção mais identificada pelos avaliadores, na sondagem que antecedeu a intervenção, foi alegria, o que converge com outros estudos com indivíduos videntes (Ekman, Sorenson \& Friesen, 1969; Ekman \& Friesen, 1971) e com deficiência visual (Anzano \& Rubio, 1995; Castanho, 1996; Castanho et al., 2003; Costa el al., 2005). Esse dado pode estar relacionado ao fato da alegria ser um sentimento positivo e como aponta Otta (1994), crianças têm mais facilidade em produzir expressões positivas do que negativas, possivelmente porque ela é mais aceita e valorizada pelos pais e professores.

A dificuldade na expressividade de tristeza pode ter acontecido em função da programação de demandas para que ela ocorresse, que talvez não tenha sido suficiente para evocá-la da forma mais natural possível. Uma hipótese é que poucas pessoas conseguem agir naturalmente sobre os músculos da tristeza, mas, após tentativas e treinos, um número considerável de pessoas pode conseguir. No presente estudo, após a intervenção, todos os participantes apresentaram a expressão facial de tristeza. No entanto, um aspecto precisa ser considerado. Muitas pessoas, quando expressam tristeza, apresentam, de forma complementar, outros componentes não verbais, como os ombros caídos e a cabeça baixa ("cabisbaixo"). Este 
movimento da cabeça inclinada sobre o peito é uma característica muito presente na expressividade desta emoção.

Com os dados obtidos por evocação instrucional foi possível também comparar indicadores obtidos com diferentes formas de registro da expressividade. Considerando os aspectos metodológicos que envolvem cada tipo de registro e a possibilidade de se coletar, ao mesmo tempo, o ápice da expressividade de uma emoção e o seu contínuo (início, meio e fim), no presente estudo foram utilizadas as duas formas de registro, por fotografias e por filmagens. Na análise do conjunto geral de dados, poucas diferenças foram observadas entre as duas formas de registro das expressões faciais de emoções, ou seja, ambas foram favoráveis à identificação do impacto do programa. Uma hipótese para estas semelhanças é a de que o registro por fotografia captou com precisão o ápice da expressividade facial das emoções, não comprometendo, portanto, as avaliações.

No entanto, cabe reconhecer que, no julgamento de algumas emoções, ocorreram divergências entre os dados obtidos com as duas formas de registros. Estas diferenças foram mais presentes na avaliação das expressões faciais de medo e surpresa, para as quais os dados da filmagem permitiram melhor diferenciação. Isso pode ter ocorrido por se tratar de emoções cuja expressão envolve aspectos topográficos com certa semelhança e, nesse caso, a continuidade início, meio e fim, viabilizada pela filmagem, fornece pistas mais confiáveis ou completas dos sinais faciais característicos dessas emoções do que apenas o seu ápice (fotografias).

Esta sensibilidade do registro por filmagem foi apontada por Ekman e Friesen (1975), embora não se negue a importância e a validade de estudos que utilizam fotografia, mais comumente utilizada nas pesquisas de expressividade de emoções pela face (Silva, 1986). Como as duas formas de registro apresentam vantagens e desvantagens, a utilização de fotografias e filmagens em um mesmo estudo é recomendada, apesar de poucas pesquisas terem explorado esta possibilidade. Tanto no contexto internacional (Anzano \& Rubio, 1995; Galati, Scherer \& Ricci-Bitti, 1996; Matsumoto \& Willingham, 2009; Tinti, 2003) como no Brasil (Castanho, 1996; Castanho et al., 2003; Costa et al., 2005), os estudos têm utilizado apenas uma forma de registro, carecendo-se de pesquisas que comparem os dados obtidos por fotografia e filmagem. Em verdade, poucas pesquisas têm utilizado uma abordagem multimodal de julgamento das expressões faciais de emoções, ou seja, com diferentes avaliadores e procedimentos.

Nos estudos sobre a expressividade facial de emoções (Anzano \& Rubio, 1995; Castanho, 1996; Castanho et al., 2003), o julgamento tem ocorrido, predominantemente, por juízes treinados. Em outros estudos, os avaliadores foram grupos de jovens não especialistas (Costa et al., 2005; Galati, et al., 1996; Silva, 1986) e que passaram 
por algum tipo de treinamento na tarefa específica de julgamento (Silva, 1986). Têm sido também utilizados grupos diversos de julgadores, como crianças, adolescentes e jovens (Legal, 1996) e pessoas não familiares e familiares às crianças (mães) (Buck, Miller \& Caul, 1974; Buck, 1975). No presente estudo, as expressões faciais de emoções dos participantes foram analisadas por juiz treinado, por pais e por professoras das crianças.

Segundo Ekman e Friesen (1975) e Silva (1986), o treinamento de juízes, mais precisamente, o treino da discriminação dos sinais característicos de uma emoção em cada área da face é um procedimento importante para aprimorar o julgamento da expressão facial de emoções. Esse treino possibilita uma avaliação mais fidedigna da expressividade de emoções na face.

O treino de avaliadores é especialmente necessário quando se avalia as expressões faciais, por exemplo, de surpresa e medo, porque ambas apresentam mudanças nos mesmos grupos musculares: sobrancelhas, olhos e boca (Ekman, \& Friesen, 1975). Embora haja algumas semelhanças entre as duas emoções, os níveis de tensão, principalmente nos músculos da área dos olhos e boca, variam de uma para outra, o que permite a diferenciação. O fato dos olhos ficarem mais abertos, as sobrancelhas se ergueram e a testa formar linhas horizontais na expressividade das duas emoções (Ekman \& Friesen, 1975), pode confundir os avaliadores.

No que se refere ao julgamento por familiares e conhecidos das crianças, por exemplo, pais e professores, é possível que os avaliadores fiquem mais sob o controle da expressividade emocional comumente percebida nas crianças, sendo mais sensíveis a esses desempenhos. Segundo Godoy (2007), o ambiente familiar e o escolar estimulam e propiciam o aprimoramento da expressividade emocional de forma mais natural. Assim, a demanda para que pais e professores julguem as expressões faciais de emoções ganha uma função maior, além do julgamento em si, já que confere validade social à avaliação realizada. Adicionalmente, pode levar pais e professores a ficarem mais atentos a estes desempenhos, consequenciando-os e, assim, contribuindo para o seu refinamento e para a manutenção e generalização das aquisições no decorrer do tempo e para outros contextos, além do familiar e escolar.

No presente estudo pais e professoras foram julgadores igualmente confiáveis das expressões faciais de seus filhos e alunos, respectivamente. Houve maior concordância do que discordância entre as avaliações desses avaliadores, entre si e com relação ao juiz, tanto antes como depois da intervenção. Considerando ainda a avaliação dos significantes, os dados da pesquisa apontaram que, no geral, os pais e professoras apresentaram mais dificuldade em julgar as expressões quando não tinham opções de escolha, ou seja, quando tinham que nomear livremente a emoção. 
Comparando-se os dados de evocação da expressividade facial de emoção por meio de demandas naturais e por meio de instruções, poucas diferenças foram observadas, ou seja, ambas as formas de evocação foram sensíveis em produzir as seis emoções básicas na face dos nove participantes na avaliação de pós-teste.

Considerando as dificuldades que envolvem estudos sobre esta temática, por exemplo, a escolha de estímulos e demandas para evocar determinada emoção, pode-se questionar se as instruções, situações e prompts utilizados foram suficientemente efetivos para tal. Outra dificuldade neste tipo de estudo é quanto ao registro das expressões faciais de emoções por fotografias, que exige destreza do pesquisador em captar a expressão no seu ápice. Para treino deste procedimento, sugere-se a realização de estudos piloto em que o pesquisador registre, por exemplo, expressões faciais de crianças, com e sem deficiência visual, e submeta as fotografias à avaliação por juízes, como ocorreu no estudo de Ferreira (2012).

\section{Considerações finais}

Por se tratar de um estudo que comparou diferentes formas de evocação, registro e julgamento de expressões faciais de emoções, cabem algumas considerações sobre os cuidados na utilização dos diferentes procedimentos. No que se refere à evocação, para permitir que as demandas evocadoras fossem familiares e próximas às já vivenciadas pela criança, foi importante a sondagem com pais, professoras e com a própria criança, de situações e eventos em que a criança sentia, expressava e vivenciava cada emoção. A partir das informações coletadas, pôde-se programar os procedimentos de avaliação pré-teste e pós-teste e adaptá-los em vários detalhes às características das crianças, sem perder a padronização e o realismo dos estímulos apresentados e das respostas avaliadas. Buscou-se, também, aproximar as demandas de avaliação às situações vivenciadas pela criança, já que estímulos similares nem sempre evocam a mesma emoção em todas as pessoas.

Mesmo com vários estudos-piloto, a escolha dos procedimentos para evocar a expressividade de emoções pela face não é tarefa fácil, principalmente, no que se refere às emoções negativas, que esbarram em questões éticas da pesquisa com seres humanos. Ao conduzir estudos que apresentem esta metodologia, é tarefa do pesquisador explicitar para os pais os procedimentos que serão adotados com as crianças, e solicitar que os pais, e também os professores, indiquem qualquer relato de desconforto por parte da criança. 


\section{Referências}

Anzano, S. M., \& Rubio, J. M. L. (1995). Entrenamiento en habilidades sociales a niños con ceguera congénita. In F. G. Rodrígues, J. M. L. Rubio \& L. J. Expósito (Orgs.), Habilidades sociales y salud (pp. 147-183). Madrid: Pirámides.

Buck, R. (1975). Nonverbal communication of affect in children. J ournal of Personality and Social Psychology, 31(4), 644-653.

Buck, R., Miller, R., \& Caul, W. S. (1974). Sex, personality and physiological variables in the communication of affect via facial expressions. Journal of Personality and Social Psychology, 30(4), 587-596.

Castanho, A. R. S. P. (1996). A face de crianças deficientes visuais: Expressões de emoções e percepção social de seus sorrisos (Tese de Doutorado). Universidade de São Paulo, São Paulo, SP, Brasil.

Castanho, A. R. S. P., Moifrel, A. C. B., Severiano, E., \& Ribeiro, V. R. (2003). Gestos não-verbais espontâneos e canais de expressão emocional voluntária em deficientes visuais. Revista Benjamin Constant, $26 . \quad$ Recuperado de http://www.ibc.gov.br/images/conteudo/revistas/benjamin_con stant/2003/edicao-26dezembro/Nossos_Meios_RBC_RevDez2003_Artigo_3.pdf.

Costa, C. S. L., Del Prette, A., Cía, F., \& Del Prette, G. (2005). Sentimentos expressos por gêmeas idênticas (cega e vidente): Comparando três procedimentos de identificação. Psico, 36(2), 205-211.

Del Prette, Z.A.P., \& Del Prette, A. (2005). Habilidades sociais na infância: Teoria e prática. Petrópolis: Vozes.

Eibl-Eibesfeldt, I. (1975). Similarities and differences between cultures in expressive movements. In R. A. Hinde (Ed.), Nonverbal communication (pp. 297-314). London: Cambridge University Press.

Ekman, P. (2004). Emotions revealed: Recognizing faces and feelings to improve communication and emotional life. New York: Henry Holt and Company.

Ekman, P., \& Friesen, W. V. (1971). Constants across cultures in the face and emotion. Journal of Personality and Social Psychology, 17, 124-129.

Ekman, P., \& Friesen, W. V. (1975). Unmasking the face. A guide to recognizing emotions from facial cues. Cambridge: Malor Books.

Ekman, P., Sorenson, E. R., \& Friesen, W. V. (1969). Pan-cultural elements in facial displays of emotion. Science, 164, 86-88.

Ferreira, B. C. (2008). Identificação de sentimentos e desempenho empático em crianças deficientes visuais e videntes: Um estudo comparativo e multimodal (Dissertação de Mestrado). Programa 
de Pós-Graduação em Educação Especial, Universidade Federal de São Carlos, SP, Brasil.

Ferreira, B. C. (2012). Expressões faciais de emoções de crianças deficientes visuais e videntes: Avaliação e intervenção sob a perspectiva das Habilidades sociais (Tese de Doutorado). Programa de Pós-Graduação em Psicologia, Universidade Federal de São Carlos, SP, Brasil.

Ferreira, B. C. \& Del Prette, Z. A. P. (2013). Programa de expressividade facial de emoções e habilidades sociais de crianças deficientes visuais e videntes. Psicologia: Reflexão e Crítica, 26(2), 327-338.

Galati, D., Scherer, K. R., \& Ricci-Bitti, P. E. (1996). Voluntary facial expression of emotion: Comparing congenitally blind with normally sighted encoders. Journal of Personality and Social Psychology, 73, 1363-1380.

Godoy, A. M. A. (2007). Indicadores de empatia em crianças com baixa visão e em seus pais: Um estudo de caso (Dissertação de Mestrado). Programa de Pós-Graduação em Educação Especial, Universidade Federal de São Carlos, São Carlos, Brasil.

Grosselin, P., Kirouac, G., \& Doré, F. Y. (1997). Components and recognition of facial expression in the communication of emotion by actors. In P. Ekman \& E. L. Rosenberg (Eds.), What the face reveals (pp. 243-267). New York: Oxford University Press.

Laplane, A. L. F., \& Batista, C. G. (2008). Ver, não ver e aprender: a participação de crianças com baixa visão e cegueira na escola. Cadernos Cedes, 28, 209-227.

Legal, E. J. (1996). Expressões faciais de emoções: Desenvolvimento da percepção assimétricas (Dissertação de Mestrado). Programa de Pós-Graduação em Psicologia Experimental, Universidade de São Paulo, São Paulo, Brasil.

Matsumoto, D., \& Willingham, B. (2009). Spontaneous facial expressions of emotion of congenitally and noncongenitally blind individuals. Journal of Personality and Social Psychology, 96(1), 1-10.

Miguel, F. K. (2015). Psicologia das emoções: uma proposta integrativa para compreender a expressão emocional. PsicoUSF, 20(1), 153-162.

Otta, E. (1994). O sorriso e seus significados. Petrópolis: Vozes.

Plutchik, R. (2002). Emotions and life: Perspectives from psychology, biology and evolution. Washington, DC: American Psychological Association.

Silva, A. A. (1986). Julgamento de expressões faciais de emoções: Fidedignidade, erros mais frequentes e treinamento (Tese de Doutorado). Programa de Pós-Graduação em Psicologia, Universidade de São Paulo, São Paulo, Brasil. 
Tinti, C. (2003). Spontaneous facial expressions in congenitally blind and sighted children aged 8-11. Journal of Visual Impairment \& Blindness, 97, 418-428.

Tröster, H, \& Brambring, M. (1992). Early social-emotional development in blind infants. Child: Care, health and development, 18, 207-227.

\section{Endereço para correspondência \\ Bárbara Carvalho Ferreira}

Universidade Federal dos Vales do Jequitinhonha e Mucuri

Faculdade Interdisciplinar em Humanidades (FIH) - Campus JK

Rodovia MGT 367 - Km 583, 5000, Alto da Jacuba, CEP 39100-000, Diamantina MG, Brasil

Endereço eletrônico: barbaracarvalho_ufvjm@yahoo.com.br

\section{Zilda Aparecida Pereira Del Prette}

Universidade Federal de São Carlos - UFSCar

Alameda das Ameixeiras, 60, Parque Faber, CEP 13561-358, São Carlos - SP, Brasil

Endereço eletrônico: zdprette@ufscr.br

Almir Del Prette

Universidade Federal de São Carlos - UFSCar

Alameda das Ameixeiras, 60, Parque Faber, CEP 13561-358, São Carlos - SP, Brasil

Endereço eletrônico: adprette@ufscr.br

Recebido em: 26/10/2015

Reformulado em: 18/07/2017

Aceito em: 02/08/2017

\section{Notas}

* Professora Adjunta da Universidade Federal dos Vales do Jequitinhonha e Mucuri (UFVJM/ Campus Diamantina). Doutora em Psicologia pela Universidade Federal de São Carlos (UFSCar).

** Professora Titular da Universidade Federal de São Carlos (UFSCar). Doutora em Psicologia pela Universidade de São Paulo. Membro do Instituto Nacional de Ciência e Tecnologia (INCT-ECCE).

*** Professor da Universidade Federal de São Carlos (UFSCar). Doutor em Psicologia pela Universidade de São Paulo.

Este artigo de revista Estudos e Pesquisas em Psicologia é licenciado sob uma Licença Creative Commons Atribuição-Não Comercial 3.0 Não Adaptada. 